\title{
Histogram Bins Matching Approach for CBIR Based on Linear grouping for Dimensionality Reduction
}

\author{
Dr. H. B. Kekre \\ MSTME, NMIMS University, Mumbai, India \\ E-mail: hbkekre@yahoo.com \\ Kavita Sonawane \\ MSTME, NMIMS University, Mumbai, India, \\ E-mail: kavitavinaysonawane@gmail.com
}

\begin{abstract}
This paper describes the histogram bins matching approach for CBIR. Histogram bins are reduced from 256 to 32 and 16 by linear grouping and effect of this dimensionality reduction is analyzed, compared, and evaluated. Work presented in this paper contributes in all three main phases of CBIR that are feature extraction, similarity matching and performance evaluation. Feature extraction explores the idea of histogram bins matching for three colors R, G and B. Histogram bin contents are used to represent the feature vector in three forms. First form of feature is count of pixels, and then other forms are obtained by computing the total and mean of intensities for the pixels falling in each of the histogram bins. Initially the size of the feature vector is 256 components as histogram with the all 256 bins. Further the size of the feature vector is reduced to 32 bins and then 16 bins by simple linear grouping of the bins. Feature extraction processes for each size and type of the feature vector is executed over the database of 2000 BMP images having 20 different classes. It prepares the feature vector databases as preprocessing part of this work. Similarity matching between query and database image feature vectors is carried out by means of first five orders of Minkowski distance and also with the cosine correlation distance. Same set of 200 query images are executed for all types of feature vector and for all similarity measures. Performance of all aspects addressed in this paper are evaluated using three parameters PRCP (Precision Recall Cross over Point), LS (longest string), LSRR (Length of String to Retrieve all Relevant images).
\end{abstract}

Index Terms - Histogram bins, linear grouping, count of pixels, total intensities Mean, PRCP, LS, LSRR.

\section{INTRODUCTION}

Image retrieval is one of the vast areas of research where researchers are working for various different aspects of content based image retrieval (CBIR). Major components to be addressed in CBIR are feature extraction, feature matching, query specification and performance evaluation. Feature extraction mainly based on the three primary contents of the image that are color, texture, and shape [1]-[4].There are three major categories of texture -based techniques, namely, probabilistic/statistical, spectral, and structural approaches. Shape representations can be categorized into two types as boundary based or region based. A boundary based representation uses only the outer boundary characteristics of the object, while a region based representation uses the entire region. Shape features may also be local or global. Local shape features are obtained from the subpart of the image or object whereas global shape feature considers the entire object. [5]-[7]. Color is most widely used visual feature which is simple and robust to represent. Various techniques are developed in different color spaces. Focusing on these primary contents individually and by combining them various methods are designed and developed for feature extraction in image retrieval and pattern matching applications. [8]-[10]. Instead of using only one content for feature representation, it has been found by many researchers that combination of them like, color with texture or color and shape vice versa or combining all three produces better results [7-8], [11][13]. Many have worked with partitioning of an image into different regions then for each region the color histogram will be computed called local histograms. These histograms then will be used as feature vectors for comparing the images. Various techniques have been invented for image retrieval based on histogram processing. Histogram is one of the simple features of the image that takes simple computations and reduces the computational complexity. It is widely used in CBIR field because of the property that it is invariant to scaling and rotation [14]-[16]. In this paper the proposed methods are mainly focusing on the color histogram technique. Work done in this paper is experimented with database of 2000 RGB images. It includes 20 classes where few classes are taken from Wang database [17]. Each database image will be separated into $R, G$ and $b$ components and for each component a histogram will be computed separately. Further these R, G and B 
histogram bins used as feature vectors and also by computing different features from histogram bins data new features are obtained and feature vector databases are prepared for all 2000 images in the database. Work proposed in this paper is organized as follows. Section II describes algorithmic view of the proposed techniques for feature extraction phase along with preprocessing work done. Section III discusses the similarity measures used for image indexing and retrieval along with the performance evaluation parameters. Section IV presents the experimental set up and Section $\mathrm{V}$ presents the results and discussions followed by conclusion in Section VI.

\section{Algorithmic VIEW OF THE PROPOSED TeChNIQUES}

Proposed algorithms are designed for feature extraction basically focusing on the color contents of the image. Color content is the primary image visual feature which is simple and robust to extract. It is invariant to scaling and rotation transformation. Color feature can be represented in various different color descriptor formats such as color coherence vector, color structure, color spaces, cumulative histograms, local color histograms Global color histograms, Color correlogram etc [15][18].

\section{A. Histogram Histogram}

Image histogram is a graphical representation of the intensity distribution in a digital image. In simple words image histogram is just a bar graph of pixel intensities. Pixel intensities are plotted along with the $\mathrm{x}$ axis and numbers of occurrences for each of these intensities are plotted across y axis.

The purpose of a histogram is to take the data (pixelsgrey level information) that is collected from a image and then display it graphically to view the distribution of the data. Histogram gives summary of count of pixels in the number of bins. Histogram bins are representing the no of grey levels in the image. By default Matlab generates 256 bins for the image histogram that represents 0 to 255 intensity levels of the image. [19-20].

We are using the color histograms for the image representation and comparison. We follow the following framework based on color histograms for the image under feature extraction process. Different aspects considered for this histogram based features and their use are explained below.

\section{B. Feature Extraction Frame Work for Proposed Algorithms}

Framework shown in Figure. 1 is briefing the idea of proposed algorithms as part of feature extraction phase executed and explored in this paper. There are different types of feature vectors computed and each type of feature vector is stored in separate databases. To have the multiple types of features, the algorithms used for feature extraction and representation are explained below. First two, are the basics or say common steps for all types of features to be extracted. Step three onwards there are little variations used in histogram bins data extracting and representing process. One variation is based on the dimension of the feature vector. Other one is the form of using the histogram bins data.

As shown in Figure 1 Feature extraction starts with first two steps:

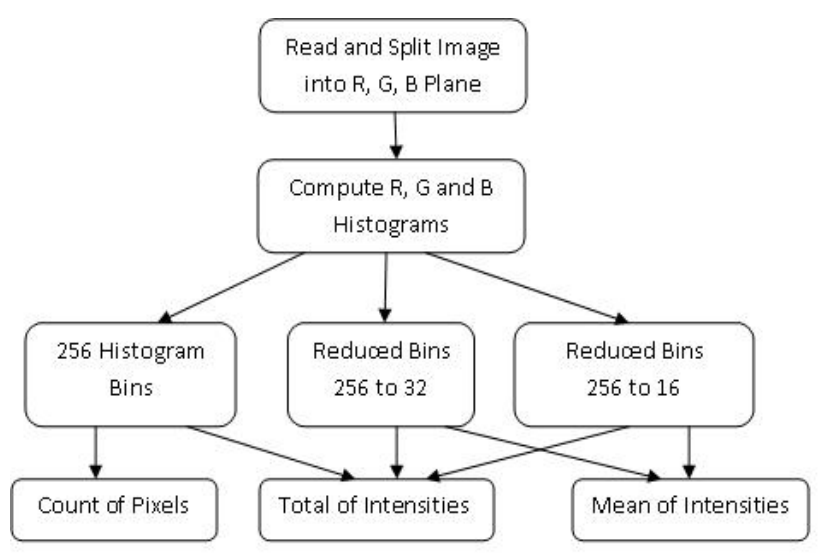

Figure 1. Histogram Based Feature Extraction Framework

Step 1: Read the image from database and split it into R, $\mathrm{G}$ and $\mathrm{B}$ planes.

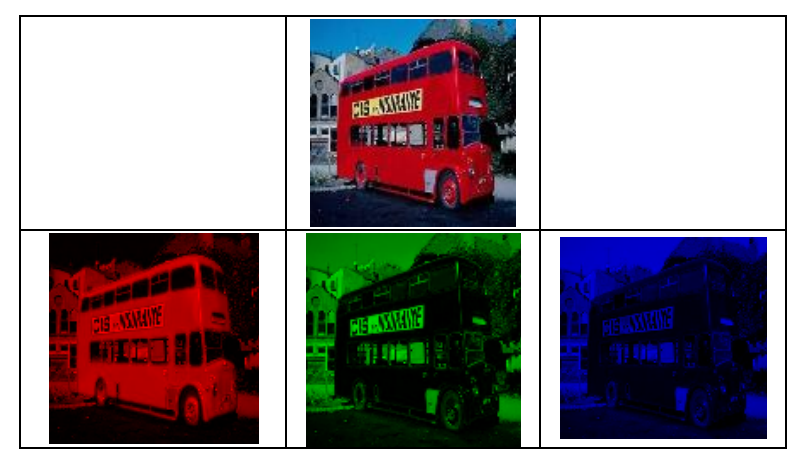

Figure 2. Bus Image with R, G and B planes Separated

Step 2: Compute the R, G and B histograms

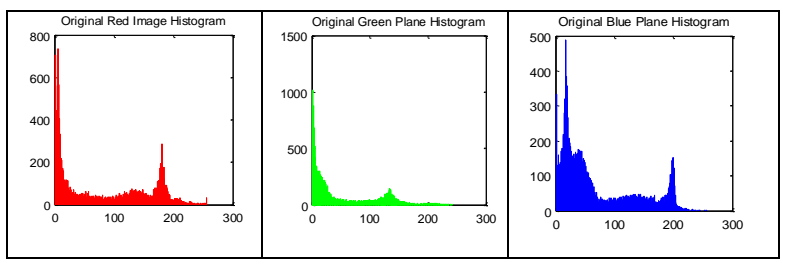

Figure 3. R, G and B Plane Histograms for Bus Image

Step3: Each histogram (In MATLAB) is represented by 256 bins for each intensity from the range 0 to 255 . Initially we have used all 256 bins data as feature vector. Image features details are given as follows.

Step 3 A: Feature Dimension: 256 Bins

Feature vector type

i. Count of Pixels,

ii. Total of Intensities into each bin: 
R_total256, G_total 256, B_total256.

Step 3 B: Reducing the size of feature vector from 256 to 32 and 16 by simple linear grouping of 8 and 16 histogram bins respectively. It is shown in Fig.4.

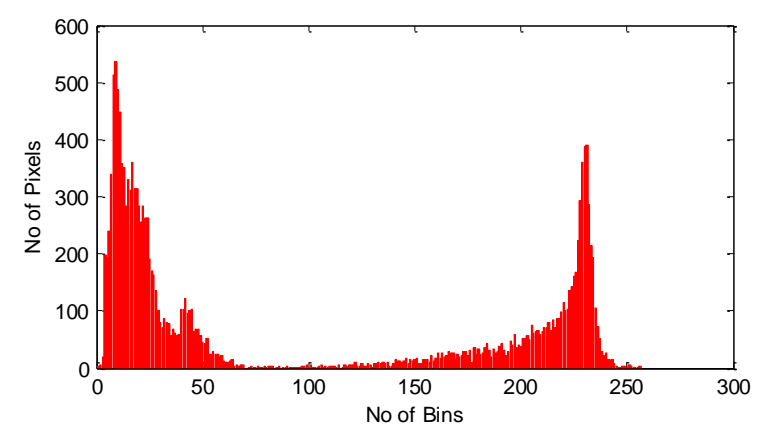

Figure 4. Original Histogram 256 Bins

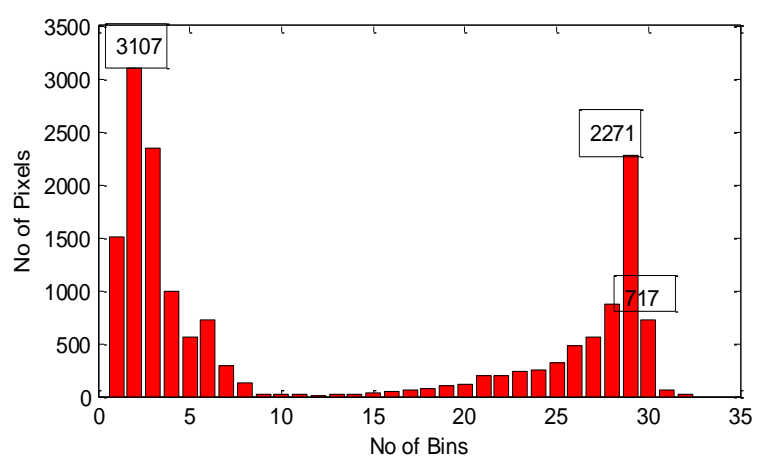

Figure 5. Linear Grouping of 8 bins of Histogram for Dimension Reduction from 256 to 32 Bins

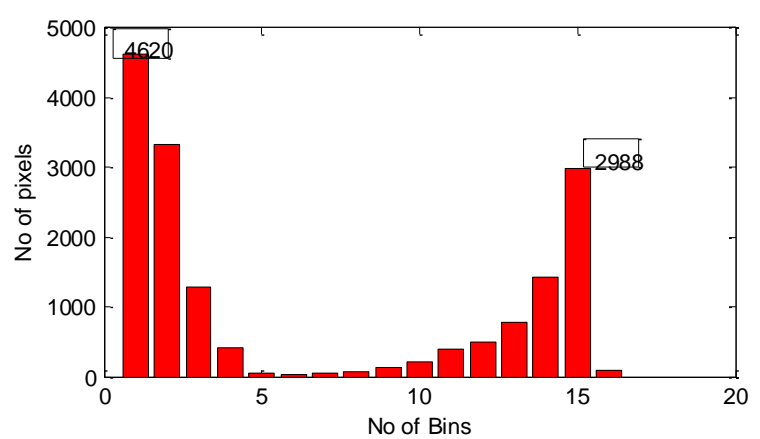

Figure 6. Linear Grouping of 16 bins of Histogram for Dimension Reduction from 256 to 16 Bins

According to this we are linearly grouping the 8 consecutive bins of histogram till 256. Linear grouping is nothing but adding total pixels falling in those consecutive 8 bins. This gives the set of 32 bins that is what the dimension of feature vector reduced to 32 bins. Tonal contents in the collected as count of pixels are represented in following forms to be used as feature vectors.

Step 3 C Feature Dimension: 32 Bins

Feature vector type i. Count of Pixels,

ii. Total of Intensities into each bin:

R_total32, G_total32, B_total32.

iii. Mean of Intensities:

R_Mean32, G_Mean32, B_Mean32.

Step 3 D Feature Dimension: 16 Bins

Feature vector type

i. Count of Pixels,

ii. Total of Intensities into each bin:

R_total16, G_total16, B_total16.

iii. Mean of Intensities:

R_Mean16,G_Mean16, B_Mean16.

Based on these steps different types of feature vectors are extracted with respect to color and the way of processing and representing the bins data. After feature extraction the next important phase we come across is feature matching between database and the query image. This comparison process is carried by means of similarity measures which are discussed as follows.

\section{Similarity MEASURES AND PERFORMANCE EVALUATION PARAMETERS}

These both the aspects are essential to test the flawless working of the system and to evaluate the performance of the proposed approaches based on these factors on some common ground.

\section{A. Similarity Measures:}

Once the preprocessing of feature vector database is done the user can fire the query as an example image to the system. System computes the feature vector for the same. Query image and database image feature vectors are then compared by means of the similarity measures. It is responsible for the finding the distance between them which will be interpreted in terms of relevancy with each other [21]-[25]. In this paper we have worked out five distance measures and one similarity measure i.e angular distance. The first five includes Minkowski distance from order 1 to order 5(Nomenclature used for them are L1 to L5) and Cosine correlation distance is used as sixth distance measure.

Minkowski Distance :

$$
\operatorname{Dist}_{D Q}=\left(\sum_{I=1}^{n}\left|D_{I}-Q_{I}\right|^{r}\right)^{\frac{1}{r}}
$$

Where ' $\boldsymbol{r}$ ' is a parameter, ' $\boldsymbol{n}$ ' is dimension and ' $\boldsymbol{I}$ ' is the component of Database and Query image feature vectors D and $\mathrm{Q}$ respectively.

To try effect multiple similarity measures Minkowiski order parameter $\boldsymbol{r}$ is used from order $\mathbf{1}$ to $\mathbf{5}$. 


\begin{tabular}{|l|l|}
\hline $\begin{array}{l}\text { Cosine Correlation Distance : } \\
\qquad \sqrt{[D(n)) \bullet(Q(n))}\end{array}$ & (2) \\
$\begin{array}{l}\left.\text { where } \boldsymbol{D}(\boldsymbol{n}) \text { and }\left.\boldsymbol{Q}(\boldsymbol{n})\right|^{2}|Q(n)|^{2}\right] \\
\text { feature Vectors resp. }\end{array}$ & \\
$\begin{array}{l}\text { It is computed in terms of } \cos \boldsymbol{\theta} \text { as angular } \\
\text { distance measure between query and database } \\
\text { feature vectors. }\end{array}$ & \\
\hline
\end{tabular}

Equations of the similarity measures used in this paper are given above in equation 1 and 2.

\section{B. Performance Evaluation Parameters}

Once the system is ready to face the query from the user it will compute feature vector for it. This feature vector will be compared with all database images (features) by means of similarity measure. This process generates set of images as an output for the query fired to the system. It contains the images relevant to query or some images which are irrelevant. Ideally the system should not contain any irrelevant image. But still this area has scope for researchers to work for achieving $100 \%$ results where retrieval set for any given query will have only relevant images. Whenever any new approach is being explored it should be evaluated with some scale or parameter so that the efficiency of the approach can be determined [26]-[27]. It will also help the users and the researchers to interpret that how far they from the ideal CBIR system. To do the same, we have used three parameters to evaluate the performance of the system through all possible perspectives of CBIR users. Three parameters used are namely PRCP (Precision Recall Cross over Point), LS (Longest String), and (LSRR) i.e Length of String to Retrieve all Relevant Images). Equations 3, 4 and 5 are defining these three parameters.

PRCP : Precision Recall Cross over Point

Where, precision and recall are defined as follows in equation 3 and 4 .

$$
\begin{aligned}
& \text { Precision }=\frac{\text { Relevant Retreived Images }}{\text { All Retrieved Images }} \\
& \text { Recall }=\frac{\text { Relevant Retreived Images }}{\text { All Relevant In Database }} \\
& \text { LSRR }=\frac{\text { Length of string to retreive all relevant }}{\text { Total images in database }}
\end{aligned}
$$

\section{EXPERIMENTATION DETAILS}

Performance of the CBIR systems will be evaluated when the query enters into the system and system generates the retrieval result for it. Speed of retrieval depends on the technique used for feature extraction and also the preprocessing done. Preprocessing done for any system is either preparing the feature vector database for all database images or the processing the query image based on some common criterion to bring it in acceptable format for the system.

\section{A. Preprocessing Work:}

As preprocessing work of this paper, we have executed the proposed algorithms for all the database images (i.e 2000 images) Based on the algorithms multiple feature vector databases (RGB, total of intensities, mean of intensities, count of pixels etc) for three different sizes of features i.e 256, 32 and 16 executed are prepared. Image database details are given as follows:

\section{B. Image Database}

To execute and check the performance of proposed algorithms experimentation is carried out over database of 2000 BMP images. It includes images from 20 different categories, where few categories are added from Wang database. Sample image from each of the 20 classes of images is shown below in Figure 5.

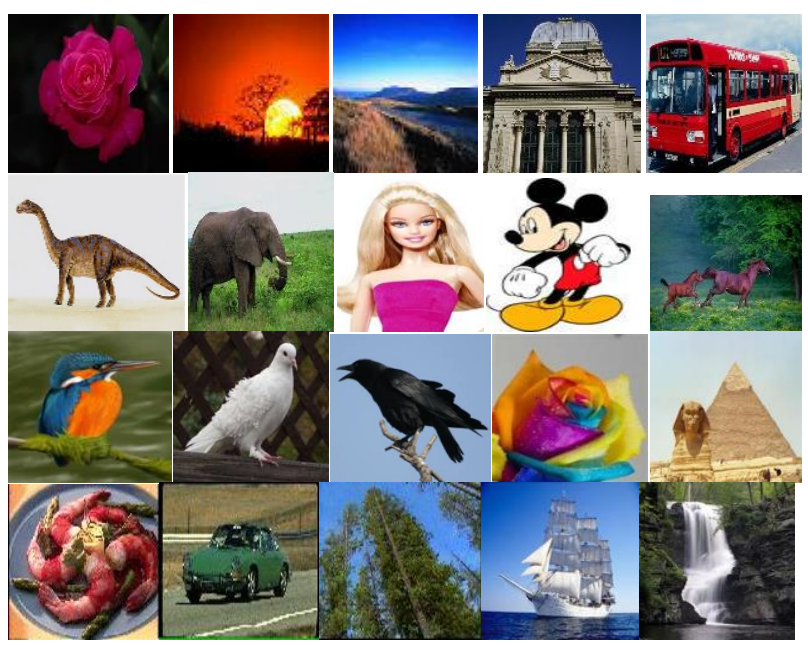

Figure 7. Sample Images from database of 2000 BMP images from 20 classes

\section{Query Specification}

As the feature vector databases are ready for all images in the database, to complete the experimentation process, A query should be fired to the system to retrieve the relevant images. This phase is called query specification. There are many ways to fire the query to the system. It includes query by content, query by class (category), query by example image etc [28]-[29]. In this experimentation the query specification used is "query by example image" approach. To check the working and active role of the system all approaches 
designed are executed with 200 query images. Set of 200 query images includes the 10 images selected randomly from each of the 20 classes of database. All approaches are executed with each of the six similarity measures (i.e first five orders of Minkowski distance (L1 to L5) and cosine correlation distance (L6) namely L1 to L6 and tested with same set of 200 images and so that their performances can be evaluated and checked on common ground.

\section{RESULTS AND DISCUSSION}

This section is presenting the results obtained for execution of each query for each approach with each similarity measure named as L1 to L6 (based n size, type of feature). The results discussed, observed, and evaluated using PRCP, LSRR, and LS parameters.

\section{A. PRCP: Precision and Recall Cross Over Point}

As said earlier this parameter is cross over point of conventional parameters precision and recall. In many CBIR systems it has been observed that when precision is high recalls falls down and if recall is high then precision falls down. This is because it depends on the threshold selected for the distances sorted in ascending order to retrieve the set of images for the given query.

In this paper instead of taking or determining the threshold on trial and error basis we used the following logic to retrieve the images. What we do here is we sort the distances of query image with database images in ascending order. In this experimental set up, total length of sorted distances is 2000 . Then we select first 100 images out of these 2000 images and we take the count of query relevant images from this 100 only. As we have 100 images of each class in the database and the count of images relevant to query is also taken out of 100; it generates the cross over point where precision and recall both are same.

$\mathrm{PRCP}=1$ is indication of the ideal system performance where we can say that set of images retrieved from the database contains all the images in the database which are relevant to query. (This set do not contains a single irrelevant image).

PRCP $=0$ is the indication of worst case performance of the system where the retrieved set of images does not contain a single image which is relevant to query. It has all the images which are irrelevant to query.

Following tables I to VI are showing the results obtained for parameter PRCP for 256 bins of histogram for feature vector type count of pixels and table VII to XII are for total of intensities. Each table is giving the results obtained for each of the six similarity measures from L1 to L5 and CD. Summary on observing these results given tables from I to XII is highlighted in Table XIII. Same process is repeated for 32 and 16 bins and the results for them are shown in table XIV to XVII. In all the tables each value in first three columns is out of 1000 (i.e total execution of 10 queries from each class).

TABLE I. PRCP: TOTAL_GL_256 BINS_L1

\begin{tabular}{|l|r|r|r|r|}
\hline Query Class & \multicolumn{1}{l|}{ R } & \multicolumn{1}{l|l|}{ G } & R OR G OR B \\
\hline Flower & 242 & 431 & 242 & 639 \\
\hline Sunset & 294 & 112 & 406 & 579 \\
\hline Mountain & 92 & 86 & 132 & 234 \\
\hline Building & 155 & 179 & 159 & 329 \\
\hline Bus & 164 & 185 & 224 & 412 \\
\hline Diansour & 513 & 563 & 454 & 638 \\
\hline Elephant & 265 & 198 & 234 & 440 \\
\hline Barbie & 566 & 566 & 554 & 684 \\
\hline Mickey & 359 & 408 & 309 & 529 \\
\hline Horses & 227 & 191 & 281 & 395 \\
\hline Kingfisher & 79 & 68 & 60 & 152 \\
\hline Dove & 443 & 441 & 375 & 488 \\
\hline Crow & 32 & 47 & 59 & 107 \\
\hline Rainbowrose & 142 & 146 & 116 & 281 \\
\hline Pyramids & 150 & 115 & 81 & 290 \\
\hline Plates & 184 & 190 & 217 & 350 \\
\hline Car & 194 & 182 & 216 & 409 \\
\hline Trees & 277 & 279 & 299 & 416 \\
\hline Ship & 203 & 125 & 159 & 316 \\
\hline Waterfall & 183 & 209 & 238 & 312 \\
\hline Total & $\mathbf{4 7 6 4}$ & $\mathbf{4 7 2 1}$ & $\mathbf{4 8 1 5}$ & $\mathbf{8 0 0 0}$ \\
\hline
\end{tabular}

TABLE II. TOTAL_GL_256 BINS_L2

\begin{tabular}{|l|r|r|r|c|}
\hline Query Class & \multicolumn{1}{|c|}{ R } & \multicolumn{1}{c|}{ G } & \multicolumn{1}{c|}{ B } & R OR G OR B \\
\hline Flower & 191 & 389 & 208 & 565 \\
\hline Sunset & 331 & 117 & 326 & 558 \\
\hline Mountain & 87 & 95 & 144 & 238 \\
\hline Building & 155 & 171 & 146 & 321 \\
\hline Bus & 140 & 164 & 205 & 390 \\
\hline Diansour & 479 & 540 & 424 & 593 \\
\hline Elephant & 259 & 217 & 263 & 465 \\
\hline Barbie & 545 & 542 & 543 & 585 \\
\hline Mickey & 295 & 365 & 279 & 438 \\
\hline Horses & 230 & 200 & 252 & 376 \\
\hline Kingfisher & 77 & 63 & 53 & 142 \\
\hline Dove & 283 & 285 & 250 & 326 \\
\hline Crow & 54 & 104 & 84 & 198 \\
\hline Rainbowrose & 96 & 119 & 114 & 225 \\
\hline Pyramids & 159 & 117 & 106 & 306 \\
\hline Plates & 216 & 189 & 237 & 390 \\
\hline Car & 173 & 164 & 215 & 376 \\
\hline Trees & 274 & 275 & 281 & 411 \\
\hline Ship & 191 & 123 & 170 & 321 \\
\hline Waterfall & 197 & 202 & 206 & 337 \\
\hline Total & $\mathbf{4 4 3 2}$ & $\mathbf{4 4 4 1}$ & $\mathbf{4 5 0 6}$ & $\mathbf{7 5 6 1}$ \\
\hline & & & & \\
\hline
\end{tabular}


TABLE III. PRCP: TOTAL_GL_256 BINS_L3

\begin{tabular}{|l|c|c|c|c|}
\hline Query Class & R & G & B & R OR G OR B \\
\hline Flower & 157 & 366 & 203 & 524 \\
\hline Sunset & 317 & 111 & 250 & 512 \\
\hline Mountain & 81 & 101 & 157 & 248 \\
\hline Building & 159 & 149 & 134 & 311 \\
\hline Bus & 109 & 121 & 152 & 297 \\
\hline Dinosaur & 510 & 572 & 444 & 618 \\
\hline Elephant & 248 & 216 & 263 & 455 \\
\hline Barbie & 544 & 545 & 543 & 586 \\
\hline Mickey & 302 & 369 & 283 & 435 \\
\hline Horses & 228 & 209 & 237 & 367 \\
\hline Kingfisher & 81 & 74 & 53 & 148 \\
\hline Dove & 158 & 161 & 165 & 212 \\
\hline Crow & 72 & 126 & 105 & 245 \\
\hline Rainbowrose & 88 & 104 & 98 & 199 \\
\hline Pyramids & 184 & 133 & 102 & 338 \\
\hline Plates & 193 & 213 & 229 & 409 \\
\hline Car & 143 & 143 & 204 & 342 \\
\hline Trees & 257 & 242 & 269 & 411 \\
\hline Ship & 173 & 122 & 179 & 323 \\
\hline Waterfall & 196 & 175 & 189 & 338 \\
\hline Total & $\mathbf{4 2 0 0}$ & $\mathbf{4 2 5 2}$ & $\mathbf{4 2 5 9}$ & $\mathbf{7 3 1 8}$ \\
\hline
\end{tabular}

TABLE IV. PRCP: TOTAL_GL_256 BINS_L4

\begin{tabular}{|l|c|l|l|c|}
\hline Query Class & R & G & B & $\begin{array}{l}\text { R OR G OR } \\
\text { B }\end{array}$ \\
\hline Flower & 182 & 374 & 200 & 544 \\
\hline Sunset & 325 & 117 & 296 & 541 \\
\hline Mountain & 81 & 100 & 154 & 243 \\
\hline Building & 158 & 164 & 139 & 319 \\
\hline Bus & 117 & 132 & 168 & 321 \\
\hline Dinosaur & 502 & 559 & 432 & 605 \\
\hline Elephant & 259 & 215 & 261 & 466 \\
\hline Barbie & 541 & 544 & 542 & 585 \\
\hline Mickey & 297 & 366 & 282 & 432 \\
\hline Horses & 225 & 205 & 237 & 365 \\
\hline Kingfisher & 80 & 69 & 55 & 148 \\
\hline Dove & 200 & 201 & 189 & 248 \\
\hline Crow & 65 & 122 & 97 & 229 \\
\hline Rainbowros & 88 & 110 & 103 & 209 \\
\hline Pyramids & 176 & 130 & 108 & 327 \\
\hline Plates & 198 & 208 & 234 & 400 \\
\hline Car & 152 & 149 & 209 & 350 \\
\hline Trees & 265 & 257 & 277 & 410 \\
\hline Ship & 179 & 127 & 175 & 325 \\
\hline Waterfall & 198 & 190 & 181 & 336 \\
\hline Total & $\mathbf{4 2 8 8}$ & $\mathbf{4 3 3 9}$ & $\mathbf{4 3 3 9}$ & $\mathbf{7 4 0 3}$ \\
\hline
\end{tabular}

TABLE V.PRCP: TOTAL_GL_256 BINS_L5

\begin{tabular}{|l|c|c|c|c|}
\hline Query Class & R & G & B & R OR G OR B \\
\hline Flower & 146 & 365 & 209 & 523 \\
\hline Sunset & 313 & 108 & 228 & 491 \\
\hline Mountain & 80 & 101 & 166 & 259 \\
\hline Building & 157 & 143 & 135 & 310 \\
\hline Bus & 101 & 113 & 144 & 286 \\
\hline Dinosaur & 513 & 576 & 452 & 628 \\
\hline Elephant & 238 & 208 & 262 & 449 \\
\hline Barbie & 544 & 546 & 544 & 586 \\
\hline Mickey & 302 & 370 & 290 & 439 \\
\hline Horses & 227 & 208 & 234 & 366 \\
\hline Kingfisher & 78 & 75 & 54 & 149 \\
\hline Dove & 146 & 143 & 152 & 205 \\
\hline Crow & 77 & 128 & 105 & 250 \\
\hline Rainbowrose & 86 & 99 & 90 & 196 \\
\hline Pyramids & 187 & 142 & 104 & 346 \\
\hline Plates & 188 & 211 & 231 & 415 \\
\hline Car & 140 & 146 & 198 & 338 \\
\hline Trees & 251 & 233 & 261 & 409 \\
\hline Ship & 161 & 122 & 176 & 312 \\
\hline Waterfall & 204 & 170 & 195 & 346 \\
\hline Total & $\mathbf{4 1 3 9}$ & $\mathbf{4 2 0 7}$ & $\mathbf{4 2 3 0}$ & $\mathbf{7 3 0 3}$ \\
\hline
\end{tabular}

TABLE VI. PRCP: TOTAL_GL_256 BINS_CD

\begin{tabular}{|l|c|c|c|c|}
\hline Query Class & R & G & B & R OR G OR B \\
\hline Flower & 178 & 296 & 224 & 517 \\
\hline Sunset & 346 & 113 & 257 & 522 \\
\hline Mountain & 108 & 100 & 136 & 257 \\
\hline Building & 148 & 140 & 140 & 300 \\
\hline Bus & 100 & 100 & 174 & 308 \\
\hline Dinosaur & 586 & 685 & 521 & 735 \\
\hline Elephant & 259 & 201 & 233 & 438 \\
\hline Barbie & 577 & 655 & 622 & 750 \\
\hline Mickey & 310 & 427 & 330 & 519 \\
\hline Horses & 257 & 232 & 294 & 420 \\
\hline Kingfisher & 77 & 65 & 63 & 156 \\
\hline Dove & 93 & 133 & 146 & 178 \\
\hline Crow & 56 & 95 & 87 & 198 \\
\hline Rainbowrose & 89 & 122 & 92 & 219 \\
\hline Pyramids & 137 & 111 & 113 & 298 \\
\hline Plates & 214 & 195 & 216 & 389 \\
\hline Car & 191 & 167 & 217 & 394 \\
\hline Trees & 228 & 236 & 230 & 361 \\
\hline Ship & 160 & 117 & 160 & 289 \\
\hline Waterfall & 201 & 217 & 215 & 360 \\
\hline Total & $\mathbf{4 3 1 5}$ & $\mathbf{4 4 0 7}$ & $\mathbf{4 4 7 0}$ & $\mathbf{7 6 0 8}$ \\
\hline
\end{tabular}


TABLE VII. PRCP: COUNT OF PIXELS_256 BINS_L1

\begin{tabular}{|c|c|c|c|c|}
\hline Query Class & R & G & B & R OR G OR B \\
\hline Flower & 369 & 468 & 366 & 645 \\
\hline Sunset & 240 & 82 & 296 & 477 \\
\hline Mountain & 88 & 99 & 142 & 253 \\
\hline Building & 162 & 187 & 154 & 310 \\
\hline Bus & 225 & 380 & 293 & 568 \\
\hline Diansour & 813 & 821 & 686 & 919 \\
\hline Elephant & 309 & 263 & 254 & 480 \\
\hline Barbie & 703 & 637 & 699 & 806 \\
\hline Mickey & 434 & 475 & 393 & 589 \\
\hline Horses & 228 & 186 & 255 & 373 \\
\hline Kingfisher & 94 & 91 & 62 & 183 \\
\hline Dove & 401 & 403 & 399 & 422 \\
\hline Crow & 70 & 130 & 124 & 263 \\
\hline Rainbowrose & 143 & 129 & 117 & 270 \\
\hline Pyramids & 268 & 180 & 116 & 431 \\
\hline Plates & 207 & 240 & 245 & 407 \\
\hline Car & 201 & 193 & 261 & 430 \\
\hline Trees & 266 & 311 & 319 & 460 \\
\hline Ship & 211 & 146 & 194 & 358 \\
\hline Waterfall & 217 & 222 & 224 & 326 \\
\hline Total & $\mathbf{5 6 4 9}$ & $\mathbf{5 6 4 3}$ & $\mathbf{5 5 9 9}$ & $\mathbf{8 9 7 0}$ \\
\hline & & & & \\
\hline
\end{tabular}

TABLE VIII. PRCP: COUNT OF PIXELS_256 BINS_L2

\begin{tabular}{|l|r|r|r|c|}
\hline Query Class & \multicolumn{1}{l|}{ R } & \multicolumn{1}{l|}{ G } & R OR G OR B \\
\hline Flower & 351 & 460 & 444 & 609 \\
\hline Sunset & 294 & 83 & 256 & 493 \\
\hline Mountain & 95 & 103 & 141 & 262 \\
\hline Building & 161 & 168 & 136 & 285 \\
\hline Bus & 212 & 381 & 268 & 584 \\
\hline Dinosaur & 485 & 553 & 434 & 606 \\
\hline Elephant & 323 & 259 & 292 & 506 \\
\hline Barbie & 557 & 554 & 554 & 596 \\
\hline Mickey & 300 & 365 & 277 & 436 \\
\hline Horses & 213 & 188 & 225 & 353 \\
\hline Kingfisher & 83 & 75 & 59 & 160 \\
\hline Dove & 385 & 388 & 374 & 400 \\
\hline Crow & 57 & 111 & 92 & 212 \\
\hline Rainbowrose & 105 & 104 & 113 & 213 \\
\hline Pyramids & 199 & 140 & 117 & 355 \\
\hline Plates & 226 & 237 & 239 & 426 \\
\hline Car & 192 & 182 & 255 & 420 \\
\hline Trees & 264 & 304 & 279 & 471 \\
\hline Ship & 321 & 128 & 185 & 423 \\
\hline Waterfall & 251 & 227 & 220 & 378 \\
\hline Total & $\mathbf{5 0 7 4}$ & $\mathbf{5 0 1 0}$ & $\mathbf{4 9 6 0}$ & $\mathbf{8 1 8 8}$ \\
\hline
\end{tabular}

TABLE IX. PRCP: COUNT OF PIXELS_256 BINS_L3

\begin{tabular}{|l|r|r|r|c|}
\hline Query Class & \multicolumn{1}{|c|}{ R } & \multicolumn{1}{c|}{ G } & \multicolumn{1}{c|}{ B } & R OR G OR B \\
\hline Flower & 341 & 442 & 440 & 603 \\
\hline Sunset & 315 & 95 & 260 & 529 \\
\hline Mountain & 95 & 103 & 150 & 270 \\
\hline Building & 141 & 157 & 124 & 271 \\
\hline Bus & 226 & 355 & 244 & 570 \\
\hline Dinosaur & 503 & 559 & 432 & 604 \\
\hline Elephant & 321 & 260 & 302 & 518 \\
\hline Barbie & 552 & 545 & 545 & 589 \\
\hline Mickey & 297 & 359 & 277 & 436 \\
\hline Horses & 200 & 198 & 210 & 350 \\
\hline Kingfisher & 80 & 72 & 62 & 153 \\
\hline Dove & 388 & 388 & 375 & 399 \\
\hline Crow & 70 & 123 & 98 & 233 \\
\hline Rainbowrose & 86 & 91 & 100 & 189 \\
\hline Pyramids & 196 & 143 & 119 & 347 \\
\hline Plates & 223 & 239 & 231 & 421 \\
\hline Car & 222 & 189 & 284 & 452 \\
\hline Trees & 243 & 289 & 249 & 455 \\
\hline Ship & 395 & 117 & 174 & 488 \\
\hline Waterfall & 260 & 198 & 205 & 394 \\
\hline Total & $\mathbf{5 1 5 4}$ & $\mathbf{4 9 2 2}$ & $\mathbf{4 8 8 1}$ & $\mathbf{8 2 7 1}$ \\
\hline & & & & \\
\hline
\end{tabular}

TABLE X. PRCP: COUNT OF PIXELS_256 BINS_L4

\begin{tabular}{|l|r|r|r|c|}
\hline Query Class & \multicolumn{1}{|c|}{ R } & \multicolumn{1}{c|}{ G } & \multicolumn{1}{c|}{ B } & R OR G OR B \\
\hline Flower & 343 & 433 & 438 & 600 \\
\hline Sunset & 309 & 98 & 256 & 528 \\
\hline Mountain & 94 & 107 & 148 & 272 \\
\hline Building & 133 & 149 & 123 & 264 \\
\hline Bus & 236 & 343 & 216 & 560 \\
\hline Dinosaur & 511 & 571 & 445 & 617 \\
\hline Elephant & 328 & 261 & 302 & 530 \\
\hline Barbie & 553 & 546 & 546 & 590 \\
\hline Mickey & 298 & 358 & 280 & 433 \\
\hline Horses & 195 & 202 & 205 & 355 \\
\hline Kingfisher & 75 & 71 & 64 & 151 \\
\hline Dove & 392 & 388 & 375 & 402 \\
\hline Crow & 77 & 125 & 107 & 247 \\
\hline Rainbowrose & 83 & 89 & 102 & 185 \\
\hline Pyramids & 189 & 147 & 117 & 347 \\
\hline Plates & 212 & 239 & 234 & 427 \\
\hline Car & 254 & 201 & 298 & 482 \\
\hline Trees & 237 & 274 & 241 & 447 \\
\hline Ship & 419 & 118 & 187 & 524 \\
\hline Waterfall & 262 & 180 & 197 & 393 \\
\hline Total & $\mathbf{5 2 0 0}$ & $\mathbf{4 9 0 0}$ & $\mathbf{4 8 8 1}$ & $\mathbf{8 3 5 4}$ \\
\hline & & & & \\
\hline
\end{tabular}


TABLE XI. PRCP: COUNT OF PIXELS_256 BINS_L5

\begin{tabular}{|l|r|r|r|c|}
\hline Query Class & \multicolumn{1}{c|}{ R } & \multicolumn{1}{c|}{ G } & \multicolumn{1}{c|}{ B } & R OR G OR B \\
\hline Flower & 345 & 428 & 427 & 593 \\
\hline Sunset & 313 & 100 & 251 & 534 \\
\hline Mountain & 88 & 110 & 151 & 279 \\
\hline Building & 126 & 145 & 125 & 265 \\
\hline Bus & 242 & 339 & 193 & 552 \\
\hline Dinosaur & 514 & 578 & 451 & 630 \\
\hline Elephant & 328 & 257 & 303 & 537 \\
\hline Barbie & 553 & 546 & 545 & 592 \\
\hline Mickey & 301 & 363 & 284 & 437 \\
\hline Horses & 196 & 207 & 195 & 358 \\
\hline Kingfisher & 70 & 73 & 68 & 151 \\
\hline Dove & 393 & 390 & 375 & 403 \\
\hline Crow & 78 & 128 & 105 & 249 \\
\hline Rainbowrose & 79 & 83 & 99 & 175 \\
\hline Pyramids & 189 & 153 & 109 & 348 \\
\hline Plates & 210 & 229 & 231 & 428 \\
\hline Car & 268 & 197 & 297 & 495 \\
\hline Trees & 233 & 266 & 233 & 440 \\
\hline Ship & 421 & 122 & 187 & 529 \\
\hline Waterfall & 268 & 174 & 189 & 401 \\
\hline Total & $\mathbf{5 2 1 5}$ & $\mathbf{4 8 8 8}$ & $\mathbf{4 8 1 8}$ & $\mathbf{8 3 9 6}$ \\
\hline & & & \\
\hline
\end{tabular}

TABLE XII. PRCP: COUNT OF PIXELS_256 BINS_CD

\begin{tabular}{|l|r|r|r|c|}
\hline Query Class & \multicolumn{1}{c|}{ R } & \multicolumn{1}{c|}{ G } & \multicolumn{1}{c|}{ B } & R OR G OR B \\
\hline Flower & 386 & 459 & 471 & 614 \\
\hline Sunset & 288 & 96 & 235 & 481 \\
\hline Mountain & 97 & 98 & 145 & 267 \\
\hline Building & 146 & 169 & 129 & 279 \\
\hline Bus & 220 & 338 & 254 & 545 \\
\hline Dinosaur & 709 & 775 & 598 & 819 \\
\hline Elephant & 309 & 256 & 254 & 469 \\
\hline Barbie & 663 & 717 & 739 & 801 \\
\hline Mickey & 358 & 404 & 317 & 532 \\
\hline Horses & 232 & 208 & 238 & 379 \\
\hline Kingfisher & 89 & 86 & 64 & 174 \\
\hline Dove & 376 & 381 & 372 & 396 \\
\hline Crow & 66 & 129 & 126 & 267 \\
\hline Rainbowrose & 93 & 96 & 111 & 197 \\
\hline Pyramids & 228 & 157 & 120 & 399 \\
\hline Plates & 221 & 238 & 240 & 425 \\
\hline Car & 221 & 193 & 282 & 447 \\
\hline Trees & 274 & 325 & 281 & 493 \\
\hline Ship & 357 & 132 & 190 & 464 \\
\hline Waterfall & 221 & 210 & 155 & 331 \\
\hline Total & $\mathbf{5 5 5 4}$ & 5467 & 5321 & 8779 \\
\hline & & & & \\
\hline
\end{tabular}

TABLE XIII. PRCP : L1 TO L5 AND CD FOR 256 BINS COUNT AND TOTAL OF INTENSITIES

\begin{tabular}{|l|c|c|c|c|c|c|}
\hline \multirow{2}{*}{$\begin{array}{l}\text { RGB } \\
\text { PRCP OR }\end{array}$} & \multicolumn{5}{|c|}{ PRCP : 256 BINS TOTAL OF INTENSITIES } \\
\cline { 2 - 7 } & L1 & L2 & L3 & L4 & L5 & CD \\
\hline COUNT & $\mathbf{8 9 7 0}$ & 8188 & 8271 & 8354 & 8396 & $\mathbf{8 7 7 9}$ \\
\hline TOTAL & $\mathbf{8 0 0 0}$ & 7561 & 7403 & 7318 & 7303 & $\mathbf{7 6 0 8}$ \\
\hline
\end{tabular}

In above results we can see that the results are obtained separately for R, G and B colors. To improve these results further, instead of taking individual results with respect to $\mathrm{R}, \mathrm{G}$ and $\mathrm{B}$ colors ; we have combined them using OR criterion.

OR Criterion: According to this criterion image being retrieved in any one color will be retrieved in the final set. (i.e. R OR G OR B). It has brought very good improvement in the retrieval set of images similar to query. If we see the total retrieval of 200 query images for each individual color we found that the values are less than 5000. But after applying OR criterion we could retrieve more than 7000 relevant images for the total execution of 200 query images.

We have followed this application of OR criterion for execution of all 200 query images with respect to each of the six similarity measures. This is done for both types of feature vectors i.e count of pixels and total of intensities.

Summary of the results obtained for 256 bins for each similarity measure are given in table XIII. Here we can see that the best results are highlighted in yellow color. We found that here L1 and CD measures proving best among all. The best result obtained is 8970 out of 20000 , for count of pixels with L1 measure. It means precision and recall is reached to 0.44 .

Next, we have executed the same set of 200 query images for the feature vectors Total of intensities and mean of intensities with dimension 32 and 16 bins for red, green and blue intensities separately. Results obtained for red, green and blue colors considered separately are observed and here also we thought of applying the OR criterion to combine and refine these results so that retrieval can be improved. Following tables XIV to XV are presenting the results for 32 bins and tables XVII and XVIII for 16 bins after applying the OR criterion for all six distance measures.

In these tables the best results are highlighted in yellow color. It can be noticed that the L1 and L2 are doing well as compared to other measures. Cumulative results of 200 query images for total and mean of intensities are shown in table XVI and XIX for 32 bins and 16 bins respectively. 
TABLE XIV. PRCP: TOTAL_32 BINS : R OR G OR B

\begin{tabular}{|l|c|c|c|c|c|c|}
\hline Query Class & L1 & L2 & L3 & L4 & L5 & CD \\
\hline Flower & 629 & 547 & 522 & 500 & 492 & 499 \\
\hline Sunset & 575 & 553 & 547 & 532 & 525 & 492 \\
\hline Mountain & 235 & 241 & 239 & 239 & 240 & 251 \\
\hline Building & 332 & 321 & 319 & 300 & 298 & 299 \\
\hline Bus & 430 & 410 & 352 & 330 & 314 & 309 \\
\hline Dinosaur & 986 & 972 & 974 & 976 & 979 & 964 \\
\hline Elephant & 438 & 466 & 462 & 463 & 462 & 409 \\
\hline Barbie & 692 & 635 & 627 & 629 & 625 & 753 \\
\hline Mickey & 537 & 494 & 489 & 484 & 484 & 527 \\
\hline Horses & 390 & 369 & 355 & 350 & 347 & 404 \\
\hline Kingfisher & 163 & 151 & 154 & 158 & 158 & 161 \\
\hline Dove & 489 & 365 & 309 & 280 & 269 & 205 \\
\hline Crow & 174 & 240 & 257 & 271 & 275 & 237 \\
\hline Rainbowrose & 275 & 238 & 221 & 226 & 221 & 218 \\
\hline Pyramids & 304 & 333 & 347 & 352 & 365 & 296 \\
\hline Plates & 346 & 362 & 374 & 379 & 385 & 356 \\
\hline Car & 409 & 385 & 369 & 371 & 364 & 409 \\
\hline Trees & 411 & 402 & 395 & 404 & 404 & 360 \\
\hline Ship & 320 & 321 & 320 & 313 & 308 & 288 \\
\hline Waterfall & 307 & 330 & 334 & 328 & 326 & 351 \\
\hline Total & $\mathbf{8 4 4 2}$ & $\mathbf{8 1 3 5}$ & $\mathbf{7 9 6 6}$ & $\mathbf{7 8 8 5}$ & $\mathbf{7 8 4 1}$ & $\mathbf{7 7 8 8}$ \\
\hline
\end{tabular}

Table XV. PRCP: MEAN: 32 BINS : R OR G OR B

\begin{tabular}{|l|c|c|c|c|c|c|}
\hline Query Class & L1 & L2 & L3 & L4 & L5 & CD \\
\hline Flower & 613 & 608 & 604 & 606 & 606 & 610 \\
\hline Sunset & 256 & 250 & 245 & 236 & 237 & 235 \\
\hline Mountain & 304 & 328 & 339 & 338 & 337 & 318 \\
\hline Building & 386 & 373 & 366 & 362 & 362 & 372 \\
\hline Bus & 438 & 429 & 409 & 394 & 385 & 418 \\
\hline Dinosaur & 368 & 372 & 369 & 368 & 360 & 371 \\
\hline Elephant & 583 & 558 & 540 & 537 & 528 & 560 \\
\hline Barbie & 520 & 508 & 483 & 439 & 438 & 473 \\
\hline Mickey & 467 & 456 & 457 & 452 & 449 & 405 \\
\hline Horses & 430 & 394 & 385 & 374 & 374 & 396 \\
\hline Kingfisher & 108 & 126 & 134 & 147 & 149 & 125 \\
\hline Dove & 287 & 339 & 357 & 357 & 353 & 346 \\
\hline Crow & 258 & 245 & 253 & 253 & 252 & 242 \\
\hline Rainbowrose & 271 & 251 & 227 & 214 & 216 & 253 \\
\hline Pyramids & 323 & 291 & 280 & 276 & 273 & 280 \\
\hline Plates & 498 & 507 & 495 & 476 & 471 & 509 \\
\hline Car & 353 & 408 & 435 & 445 & 448 & 400 \\
\hline Trees & 413 & 370 & 356 & 353 & 349 & 375 \\
\hline Ship & 272 & 269 & 265 & 275 & 274 & 274 \\
\hline Waterfall & 544 & 494 & 456 & 433 & 429 & 495 \\
\hline Total & 7692 & 7576 & 7455 & 7335 & $\mathbf{7 2 9 0}$ & $\mathbf{7 4 5 7}$ \\
\hline
\end{tabular}

TABLE XVI PRCP : L1 TO L5 AND CD FOR 32 BINS TOTAL AND MEAN OF INTENSITIES

\begin{tabular}{|l|l|l|l|l|l|l|}
\hline RGB & \multicolumn{5}{|c|}{ PRCP : 32 BINS } \\
\cline { 2 - 8 } $\begin{array}{l}\text { PRCP } \\
\text { OR }\end{array}$ & L1 & L2 & L3 & L4 & L5 & CD \\
\hline TOTAL & $\mathbf{8 4 4 2}$ & $\mathbf{8 1 3 5}$ & 7966 & 7885 & 7841 & 7788 \\
\hline MEAN & $\mathbf{7 6 9 2}$ & $\mathbf{7 5 7 6}$ & 7455 & 7335 & 7290 & 7457 \\
\hline
\end{tabular}

TABLE XVII. PRCP: TOTAL_16 BINS R OR G OR FOR SIMILARITY MEASURES L1 TO L5 AND CD:

\begin{tabular}{|l|r|r|r|r|r|r|}
\hline Query Class & L1 & L2 & \multicolumn{1}{c|}{ L3 } & L4 & \multicolumn{1}{c|}{ L5 } & CD \\
\hline Flower & 634 & 545 & 514 & 504 & 495 & 503 \\
\hline Sunset & 576 & 549 & 541 & 534 & 533 & 479 \\
\hline Mountain & 236 & 247 & 242 & 244 & 249 & 243 \\
\hline Building & 329 & 322 & 311 & 304 & 299 & 290 \\
\hline Bus & 442 & 417 & 379 & 359 & 338 & 332 \\
\hline Dinosaur & 973 & 951 & 951 & 954 & 957 & 956 \\
\hline Elephant & 433 & 440 & 445 & 440 & 434 & 392 \\
\hline Barbie & 693 & 663 & 651 & 649 & 650 & 694 \\
\hline Mickey & 538 & 503 & 492 & 489 & 490 & 507 \\
\hline Horses & 392 & 361 & 348 & 344 & 340 & 394 \\
\hline Kingfisher & 179 & 161 & 160 & 160 & 163 & 169 \\
\hline Dove & 491 & 390 & 350 & 329 & 318 & 213 \\
\hline Crow & 263 & 281 & 290 & 291 & 295 & 278 \\
\hline Rainbowrose & 273 & 252 & 235 & 235 & 236 & 225 \\
\hline Pyramids & 324 & 346 & 368 & 374 & 377 & 310 \\
\hline Plates & 332 & 349 & 356 & 365 & 364 & 341 \\
\hline Car & 408 & 390 & 378 & 371 & 372 & 406 \\
\hline Trees & 397 & 387 & 398 & 398 & 400 & 349 \\
\hline Ship & 317 & 318 & 323 & 313 & 307 & 292 \\
\hline Waterfall & 309 & 323 & 322 & 320 & 320 & 343 \\
\hline Total & $\mathbf{8 5 3 9}$ & $\mathbf{8 1 9 5}$ & $\mathbf{8 0 5 4}$ & $\mathbf{7 9 7 7}$ & $\mathbf{7 9 3 7}$ & $\mathbf{7 7 1 6}$ \\
\hline
\end{tabular}

The next parameters used for evaluation of the proposed algorithms are LS i.e Longest String and LSRR. All 200 query images are executed to obtained results for these parameter with each color R, G and B separately.

\section{B. LS: Longest String}

As per the definition of LS parameter the results should be as high as possible to prove the best performance of the system. While retrieving the results of LS we have done the additional analysis for checking the performance of each color R, G and B. We have considered only the maximum LS obtained from the results obtained for all 10 queries from each class for $\mathrm{R}$, $\mathrm{G}$ and $\mathrm{B}$ colors separately. We have marked the color of the maximum LS. Results obtained for LS with 256 bins approach for total of intensities and counts of pixels are shown in Table XX and XXI respectively. Each value in the tables is out of 100 as we have 100 images of each class in the database. 
TABLE XVIII. PRCP: MEAN: 16 BINS : R OR G OR B FOR SIMILARITY MEASURES L1 TO L5 AND CD:

\begin{tabular}{|l|r|r|r|r|r|r|}
\hline Query Class & \multicolumn{1}{|c|}{ L1 } & L2 & \multicolumn{1}{c|}{ L3 } & \multicolumn{1}{c|}{ L4 } & \multicolumn{1}{c|}{ L5 } & \multicolumn{1}{c|}{ CD } \\
\hline Flower & 622 & 592 & 582 & 576 & 572 & 580 \\
\hline Sunset & 291 & 285 & 282 & 280 & 277 & 258 \\
\hline Mountain & 275 & 279 & 283 & 296 & 302 & 263 \\
\hline Building & 405 & 406 & 393 & 384 & 382 & 381 \\
\hline Bus & 545 & 546 & 534 & 530 & 520 & 516 \\
\hline Dinosaur & 750 & 729 & 719 & 714 & 705 & 721 \\
\hline Elephant & 576 & 568 & 537 & 517 & 509 & 558 \\
\hline Barbie & 663 & 611 & 588 & 555 & 540 & 570 \\
\hline Mickey & 495 & 482 & 469 & 462 & 458 & 431 \\
\hline Horses & 461 & 473 & 476 & 480 & 470 & 439 \\
\hline Kingfisher & 144 & 157 & 161 & 166 & 170 & 148 \\
\hline Dove & 373 & 384 & 365 & 359 & 361 & 398 \\
\hline Crow & 245 & 267 & 271 & 273 & 274 & 269 \\
\hline Rainbowrose & 263 & 242 & 236 & 221 & 216 & 247 \\
\hline Pyramids & 307 & 284 & 292 & 290 & 291 & 298 \\
\hline Plates & 473 & 462 & 449 & 446 & 435 & 452 \\
\hline Car & 471 & 479 & 494 & 503 & 509 & 473 \\
\hline Trees & 494 & 443 & 417 & 400 & 385 & 443 \\
\hline Ship & 296 & 301 & 312 & 320 & 320 & 284 \\
\hline Waterfall & 514 & 487 & 469 & 452 & 446 & 482 \\
\hline Total & $\mathbf{8 6 6 3}$ & $\mathbf{8 4 7 7}$ & $\mathbf{8 3 2 9}$ & $\mathbf{8 2 2 4}$ & $\mathbf{8 1 4 2}$ & $\mathbf{8 2 1 1}$ \\
\hline
\end{tabular}

TABLE XIX. PRCP : L1 TO L5 AND CD FOR 16 BINS TOTAL AND MEAN OF INTENSITIES

\begin{tabular}{|c|c|c|c|c|c|c|}
\hline RGB PRCP & \multicolumn{6}{|c|}{ PRCP : 16 BINS } \\
\cline { 2 - 7 } OR & L1 & L2 & L3 & L4 & L5 & CD \\
\hline TOTAL & $\mathbf{8 5 3 9}$ & $\mathbf{8 1 9 5}$ & 8054 & 7977 & 7937 & 7716 \\
\hline MEAN & $\mathbf{8 6 6 3}$ & $\mathbf{8 4 7 7}$ & 8329 & 8224 & 8142 & 8211 \\
\hline
\end{tabular}

As discussed above the Table XX shows the result of LS with the performance analysis of colors $\mathrm{R}, \mathrm{G}$ and $\mathrm{B}$. It can be observed in the table that Red color is performing better among three. The maximum LS in all distance measures is from class Dinosaur only (highlighted in yellow color). Observing the results with respect to similarity measures we found that $\mathrm{L1}$ and $\mathrm{CD}$ are better as compared to other measures. (AVG is 14.4 for L1 and 11.6 for CD and then next in queue is L2 i.e 11.3).

\section{LSRR (Length of String to Retrieve all Relevant)}

Same process is applied for the other evaluation parameter i.e LSRR. Here also we have checked the performance of R, G and B colors. Here only minimum of 10 queries from each class is taken into consideration. The only difference between two parameters is that for LSRR the result should be as low as possible; as it is the measure of the length to be traversed to collect all relevant images from database. Table XXII and XXIII are showing the LSRR results obtained for total of intensities and count of pixels for feature vector size 256 bins.

TABLE XX : LONGEST STRING FOR 256 BINS _ TOTAL of INTENSITIES

\begin{tabular}{|c|c|c|c|c|c|c|c|c|c|c|c|c|}
\hline \multirow{2}{*}{$\begin{array}{l}\text { Query Class } \\
\text { Flower }\end{array}$} & \multicolumn{2}{|c|}{ L1 } & \multicolumn{2}{|c|}{$\mathbf{L} 2$} & \multicolumn{2}{|c|}{ L3 } & \multicolumn{2}{|c|}{ L4 } & \multicolumn{2}{|c|}{ L5 } & \multicolumn{2}{|c|}{ CD } \\
\hline & 15 & $\mathrm{G}$ & 10 & $\mathrm{~B}$ & 18 & $\mathrm{G}$ & 12 & $\mathrm{G}$ & 12 & $\mathrm{G}$ & 13 & $B$ \\
\hline Sunset & 16 & $\mathrm{~B}$ & 10 & $\mathrm{~B}$ & 10 & $\mathrm{~B}$ & 9 & $\mathrm{~B}$ & 9 & $\mathrm{~B}$ & 9 & $\mathrm{R}$ \\
\hline Mountain & 3 & $\mathrm{R}$ & 4 & $\mathrm{R}$ & 4 & $\mathrm{R}$ & 5 & $B$ & 4 & $\mathrm{R}$ & 4 & $\mathrm{R}$ \\
\hline Building & 6 & $\mathrm{R}$ & 4 & $\mathrm{R}$ & 4 & $\mathrm{R}$ & 4 & $\mathrm{R}$ & 4 & $\mathrm{R}$ & 4 & G \\
\hline Bus & 10 & B & 5 & $\mathrm{~B}$ & 5 & $\mathrm{G}$ & 6 & G & 4 & $\mathrm{R}$ & 4 & $\mathrm{R}$ \\
\hline Diansour & 64 & G & 65 & $\mathrm{G}$ & 64 & $\mathrm{G}$ & 66 & $\mathrm{G}$ & 66 & $\mathrm{G}$ & 50 & G \\
\hline Elephant & 13 & $\mathrm{R}$ & 10 & $\mathrm{R}$ & 9 & $\mathrm{R}$ & 9 & $\mathrm{R}$ & 8 & $\mathrm{~B}$ & 7 & $B$ \\
\hline Barbie & 20 & $R$ & 17 & $\mathrm{~B}$ & 17 & $\mathrm{R}$ & 17 & $\mathrm{R}$ & 17 & $\mathrm{R}$ & 32 & $\mathrm{~B}$ \\
\hline Mickey & 39 & B & 17 & $\mathrm{G}$ & 15 & $\mathrm{G}$ & 16 & G & 17 & G & 31 & $\mathrm{G}$ \\
\hline Horses & 14 & $\mathrm{~B}$ & 9 & $\mathrm{~B}$ & 11 & $B$ & 11 & $B$ & 9 & $\mathrm{G}$ & 12 & G \\
\hline Kingfisher & 4 & $\mathrm{G}$ & 4 & $\mathrm{R}$ & 4 & $\mathrm{R}$ & 5 & $\mathrm{R}$ & 5 & $\mathrm{~B}$ & 4 & $\mathrm{R}$ \\
\hline Dove & 33 & $\mathrm{G}$ & 16 & $\mathrm{~B}$ & 7 & $\mathrm{G}$ & 8 & G & 8 & $\mathrm{R}$ & 6 & $B$ \\
\hline Crow & 5 & G & 11 & $\mathrm{G}$ & 7 & $\mathrm{R}$ & 8 & G & 7 & G & 11 & G \\
\hline Rainbowrose & 6 & $\mathrm{R}$ & 4 & $\mathrm{R}$ & 5 & $\mathrm{~B}$ & 5 & $\mathrm{~B}$ & 4 & $\mathrm{R}$ & 6 & $\mathrm{R}$ \\
\hline Pyramids & 5 & $\mathrm{G}$ & 5 & $\mathrm{R}$ & 5 & $\mathrm{R}$ & 8 & $B$ & 8 & $B$ & 4 & $\mathrm{R}$ \\
\hline Plates & 6 & $\mathrm{G}$ & 9 & $\mathrm{~B}$ & 8 & $B$ & 6 & $\mathrm{R}$ & 6 & $\mathrm{R}$ & 7 & $B$ \\
\hline Car & 7 & $\mathrm{G}$ & 7 & $\mathrm{G}$ & 4 & $\mathrm{R}$ & 5 & $\mathrm{R}$ & 7 & $\mathrm{R}$ & 5 & $\bar{R}$ \\
\hline Trees & 9 & $\mathrm{G}$ & 9 & $\mathrm{R}$ & 11 & $\mathrm{R}$ & 11 & $\mathrm{R}$ & 10 & $\mathrm{R}$ & 11 & $\mathrm{R}$ \\
\hline Ship & 6 & $\mathrm{R}$ & 4 & $\mathrm{R}$ & 5 & $\mathrm{R}$ & 4 & $\mathrm{R}$ & 4 & $\mathrm{G}$ & 4 & $\mathrm{R}$ \\
\hline Waterfall & 7 & $\mathrm{~B}$ & 6 & $\mathrm{R}$ & 6 & $\mathrm{R}$ & 7 & $\mathrm{R}$ & 6 & $\mathrm{R}$ & 8 & $\mathrm{R}$ \\
\hline AVG & 14.4 & & 11.3 & & 10.95 & & 11.1 & & 10.75 & & 11.6 & \\
\hline R, G, B COUNT & 6, &, 5 & 9,4 &, 7 & 11,5 &, 4 & 9,6 & 5 & 10,6 & 4 & 10, & 5,5 \\
\hline
\end{tabular}


TABLE XXI : LONGEST STRING FOR 256 BINS _COUNT OF PIXELS

\begin{tabular}{|c|c|c|c|c|c|c|c|c|c|c|c|c|}
\hline \multirow{2}{*}{$\begin{array}{l}\text { Query Class } \\
\text { Flower }\end{array}$} & \multicolumn{2}{|c|}{ L1 } & \multicolumn{2}{|c|}{$\mathbf{L} 2$} & \multicolumn{2}{|c|}{ L3 } & \multicolumn{2}{|c|}{ L4 } & \multicolumn{2}{|c|}{ L5 } & \multicolumn{2}{|c|}{$C D$} \\
\hline & 15 & $\mathrm{G}$ & 25 & $B$ & 31 & $\mathrm{G}$ & 28 & $\mathrm{G}$ & 28 & G & 26 & B \\
\hline Sunset & 9 & $B$ & 8 & $R$ & 7 & $\mathrm{R}$ & 6 & $\bar{R}$ & 8 & B & 7 & $\bar{R}$ \\
\hline Mountain & 5 & $\bar{R}$ & 4 & $R$ & 5 & B & 4 & $\mathrm{G}$ & 4 & $\bar{G}$ & 4 & $\mathrm{R}$ \\
\hline Building & 5 & $R$ & 4 & $R$ & 4 & $\mathrm{R}$ & 5 & $R$ & 6 & B & 5 & $B$ \\
\hline Bus & 10 & $\mathrm{R}$ & 12 & B & 10 & B & 12 & G & 12 & $\bar{G}$ & 13 & $\mathrm{G}$ \\
\hline Diansour & 83 & G & 66 & G & 64 & $\mathrm{G}$ & 66 & $\mathrm{G}$ & 66 & G & 75 & $\mathrm{G}$ \\
\hline Elephant & 16 & $B$ & 11 & $\bar{R}$ & 9 & $\bar{R}$ & 12 & $\bar{R}$ & 9 & $R$ & 9 & $\bar{R}$ \\
\hline Barbie & 35 & $\mathrm{R}$ & 17 & $\mathrm{~B}$ & 17 & $\mathrm{R}$ & 17 & $R$ & 17 & $R$ & 42 & $\mathrm{R}$ \\
\hline Mickey & 40 & $\mathrm{G}$ & 19 & $R$ & 17 & $R$ & 15 & $R$ & 15 & $R$ & 38 & $\mathrm{R}$ \\
\hline Horses & 10 & $\mathrm{G}$ & 10 & B & 7 & $\bar{R}$ & 7 & $\bar{R}$ & 7 & $\bar{G}$ & 12 & B \\
\hline Kingfisher & 4 & $B$ & 4 & $\mathrm{G}$ & 5 & $G$ & 4 & $\mathrm{R}$ & 4 & $\mathrm{G}$ & 4 & $\bar{R}$ \\
\hline Dove & 36 & $\mathrm{R}$ & 39 & $\mathrm{G}$ & 38 & $\mathrm{R}$ & 38 & $\mathrm{R}$ & 38 & $R$ & 43 & B \\
\hline Crow & 9 & $\mathrm{G}$ & 6 & $G$ & 5 & $\mathrm{G}$ & 5 & G & 5 & $R$ & 5 & $\mathrm{R}$ \\
\hline Rainbowrose & 5 & $\mathrm{R}$ & 5 & B & 4 & $\mathrm{R}$ & 4 & $R$ & 5 & G & 6 & G \\
\hline Pyramids & 6 & B & 4 & $\mathrm{R}$ & 4 & $\mathrm{R}$ & 5 & $R$ & 5 & $R$ & 6 & $\mathrm{G}$ \\
\hline Plates & 7 & $R$ & 6 & G & 4 & $\mathrm{R}$ & 5 & $\mathrm{R}$ & 5 & $\mathrm{~B}$ & 7 & $\mathrm{G}$ \\
\hline Car & 7 & $R$ & 13 & $B$ & 12 & B & 11 & $R$ & 10 & $B$ & 9 & $B$ \\
\hline Trees & 9 & $\mathrm{R}$ & 10 & $B$ & 9 & $\mathrm{G}$ & 8 & G & 7 & $\bar{R}$ & 11 & B \\
\hline Ship & 6 & $\mathrm{G}$ & 8 & $\bar{R}$ & 9 & $\mathrm{R}$ & 9 & $\bar{R}$ & 8 & $\bar{R}$ & 8 & $\bar{R}$ \\
\hline Waterfall & 6 & $\mathrm{R}$ & 7 & $\mathrm{G}$ & 8 & $\mathrm{G}$ & 6 & $\mathrm{R}$ & 7 & $\mathrm{G}$ & 6 & B \\
\hline AVG & 16.15 & & 13.9 & & 13.45 & & 13.35 & & 13.3 & & 16.8 & \\
\hline RGBCOUNT & \multicolumn{2}{|c|}{$10,5,5$} & \multicolumn{2}{|c|}{$7,6,7$} & \multicolumn{2}{|c|}{1163} & \multicolumn{2}{|c|}{$14,6,0$} & \multicolumn{2}{|c|}{$8,8,4$} & \multicolumn{2}{|c|}{$8,5,7$} \\
\hline
\end{tabular}

TABLE XXII : LSRR FOR 256 BINS _ TOTAL OF INTENSITIES

\begin{tabular}{|c|c|c|c|c|c|c|c|c|c|c|c|c|}
\hline \multirow{2}{*}{$\begin{array}{l}\text { Query Class } \\
\text { Flower }\end{array}$} & \multicolumn{2}{|c|}{ L1 } & \multicolumn{2}{|c|}{ L2 } & \multicolumn{2}{|c|}{ L3 } & \multicolumn{2}{|c|}{ L4 } & \multicolumn{2}{|c|}{ L5 } & \multicolumn{2}{|c|}{$C D$} \\
\hline & 33 & G & 47 & $B$ & 46 & B & 46 & $B$ & 44 & $B$ & 50 & B \\
\hline Sunset & 48 & B & 65 & B & 67 & B & 66 & $\mathrm{R}$ & 66 & $\mathrm{R}$ & 49 & $\bar{R}$ \\
\hline Mountain & 79 & $\bar{R}$ & 79 & $\bar{R}$ & 79 & $\bar{R}$ & 78 & $\mathrm{R}$ & 78 & B & 70 & $\mathrm{R}$ \\
\hline Building & 70 & $\mathrm{R}$ & 77 & $\mathrm{R}$ & 76 & $\mathrm{~B}$ & 78 & $\mathrm{R}$ & 78 & $\mathrm{R}$ & 78 & $\mathrm{R}$ \\
\hline Bus & 51 & $\mathrm{R}$ & 72 & $\mathrm{R}$ & 74 & $\mathrm{R}$ & 75 & $\mathrm{R}$ & 75 & $\mathrm{R}$ & 56 & $B$ \\
\hline Dinosaur & 68 & $\mathrm{G}$ & 91 & $\mathrm{G}$ & 91 & $\mathrm{G}$ & 91 & $\mathrm{G}$ & 90 & $\mathrm{G}$ & 15 & $\mathrm{G}$ \\
\hline Elephant & 65 & $\mathrm{R}$ & 79 & $\mathrm{R}$ & 81 & $\mathrm{R}$ & 81 & $\mathrm{R}$ & 81 & B & 64 & $\bar{R}$ \\
\hline Barbie & 85 & $\mathrm{R}$ & 100 & $\mathrm{R}$ & 100 & $\mathrm{R}$ & 100 & $\mathrm{R}$ & 100 & $\mathrm{R}$ & 32 & $B$ \\
\hline Mickey & 87 & $\mathrm{~B}$ & 94 & $\mathrm{R}$ & 94 & $\mathrm{R}$ & 93 & $\mathrm{R}$ & 94 & $\mathrm{R}$ & 82 & $\mathrm{G}$ \\
\hline Horses & 54 & $\mathrm{~B}$ & 59 & $\mathrm{~B}$ & 58 & B & 57 & B & 56 & B & 60 & $\mathrm{R}$ \\
\hline Kingfisher & 82 & $\mathrm{~B}$ & 81 & $\mathrm{~B}$ & 83 & $\mathrm{R}$ & 83 & $\mathrm{R}$ & 83 & $\mathrm{R}$ & 78 & $B$ \\
\hline Dove & 62 & $\mathrm{G}$ & 87 & $\mathrm{R}$ & 88 & $\mathrm{R}$ & 88 & $\mathrm{R}$ & 89 & $\mathrm{R}$ & 80 & $\mathrm{G}$ \\
\hline Crow & 95 & $\mathrm{R}$ & 99 & $\mathrm{R}$ & 99 & $\mathrm{R}$ & 99 & $\mathrm{R}$ & 99 & $\mathrm{R}$ & 97 & $\mathrm{R}$ \\
\hline Rainbowrose & 82 & $\mathrm{R}$ & 90 & $\mathrm{R}$ & 90 & $\mathrm{R}$ & 90 & $\mathrm{R}$ & 90 & $\mathrm{R}$ & 90 & $\mathrm{G}$ \\
\hline Pyramids & 83 & $\mathrm{G}$ & 84 & $\mathrm{R}$ & 84 & $\mathrm{R}$ & 84 & $\mathrm{R}$ & 84 & $\mathrm{R}$ & 81 & $\mathrm{R}$ \\
\hline Plates & 63 & $\mathrm{G}$ & 73 & $B$ & 79 & $\mathrm{G}$ & 80 & $\mathrm{~B}$ & 81 & $\mathrm{G}$ & 63 & G \\
\hline Car & 71 & $\mathrm{R}$ & 69 & $\mathrm{R}$ & 73 & B & 74 & B & 74 & $\mathrm{R}$ & 64 & B \\
\hline Trees & 56 & $\mathrm{G}$ & 76 & $\mathrm{G}$ & 80 & $\mathrm{G}$ & 81 & $\mathrm{R}$ & 81 & $\mathrm{R}$ & 67 & $\mathrm{R}$ \\
\hline Ship & 65 & $\mathrm{R}$ & 81 & $\mathrm{R}$ & 82 & $B$ & 82 & $\mathrm{~B}$ & 82 & $B$ & 72 & $\mathrm{R}$ \\
\hline Waterfall & 62 & $\bar{R}$ & 69 & $\mathrm{G}$ & 68 & $\mathrm{G}$ & 68 & $\mathrm{G}$ & 68 & $\mathrm{G}$ & 66 & G \\
\hline AVG & 68.05 & & 78.6 & & 79.6 & & 79.7 & & 79.65 & & 65.7 & \\
\hline R, G, B COUNT & 10,6 & 4 & 12 & 3,5 & 10 & 4,6 & 13 & 2,5 & 12,3 & 5 & & 6,5 \\
\hline
\end{tabular}


TABLE XXIII : LSRR 256 BINS_COUNT OF PIXELS

\begin{tabular}{|c|c|c|c|c|c|c|c|c|c|c|c|c|}
\hline \multirow{2}{*}{$\begin{array}{l}\text { Query Class } \\
\text { Flower }\end{array}$} & \multicolumn{2}{|c|}{ L1 } & \multicolumn{2}{|c|}{ L2 } & \multicolumn{2}{|l|}{ L3 } & \multicolumn{2}{|c|}{ L4 } & \multicolumn{2}{|c|}{ L5 } & \multicolumn{2}{|c|}{ CD } \\
\hline & 46 & $\mathrm{G}$ & 75 & $\mathrm{G}$ & 61 & $\mathrm{G}$ & 58 & $\bar{G}$ & 58 & $\mathrm{G}$ & 48 & $\bar{G}$ \\
\hline Sunset & 76 & $B$ & 81 & $R$ & 80 & B & 58 & $\mathrm{R}$ & 60 & $\mathrm{R}$ & 42 & $R$ \\
\hline Mountain & 70 & $\mathrm{~B}$ & 84 & $\bar{R}$ & 85 & $\mathrm{R}$ & 85 & $\mathrm{R}$ & 85 & $\mathrm{R}$ & 74 & $R$ \\
\hline Building & 64 & $\mathrm{R}$ & 80 & $\mathrm{R}$ & 80 & B & 81 & B & 81 & B & 72 & $R$ \\
\hline Bus & 34 & $B$ & 42 & G & 41 & G & 46 & G & 48 & $\mathrm{G}$ & 41 & G \\
\hline Diansour & 7 & G & 87 & $\mathrm{G}$ & 87 & $\mathrm{G}$ & 87 & $\mathrm{G}$ & 87 & $\mathrm{G}$ & 9 & G \\
\hline Elephant & 58 & $\mathrm{G}$ & 51 & B & 61 & B & 63 & B & 63 & B & 52 & $R$ \\
\hline Barbie & 15 & $\mathrm{R}$ & 98 & $\bar{R}$ & 98 & $\mathrm{R}$ & 98 & $\mathrm{R}$ & 98 & $\bar{R}$ & 23 & $B$ \\
\hline Mickey & 72 & $\mathrm{R}$ & 90 & $\mathrm{R}$ & 90 & $\mathrm{R}$ & 87 & $\mathrm{R}$ & 88 & $\mathrm{R}$ & 78 & G \\
\hline Horses & 69 & G & 58 & $\mathrm{G}$ & 56 & G & 59 & G & 61 & $G$ & 61 & G \\
\hline Kingfisher & 84 & $R$ & 81 & $\mathrm{G}$ & 83 & $\mathrm{G}$ & 83 & $\mathrm{G}$ & 84 & $\mathrm{G}$ & 80 & $R$ \\
\hline Dove & 88 & $\mathrm{G}$ & 98 & $\mathrm{G}$ & 98 & G & 98 & G & 98 & $\mathrm{G}$ & 93 & $B$ \\
\hline Crow & 94 & $\mathrm{R}$ & 99 & $\mathrm{R}$ & 99 & $\mathrm{R}$ & 99 & $\mathrm{R}$ & 99 & $\mathrm{R}$ & 95 & $R$ \\
\hline Rainbowrose & 76 & $\mathrm{G}$ & 93 & B & 93 & $\mathrm{~B}$ & 93 & $\mathrm{~B}$ & 93 & $B$ & 88 & $\mathrm{G}$ \\
\hline Pyramids & 64 & $\mathrm{G}$ & 75 & $\mathrm{R}$ & 78 & $\mathrm{R}$ & 78 & $\mathrm{R}$ & 79 & $\mathrm{R}$ & 68 & $\mathrm{G}$ \\
\hline Plates & 57 & G & 53 & G & 59 & G & 63 & G & 66 & G & 56 & G \\
\hline Car & 63 & B & 62 & $\mathrm{~B}$ & 61 & B & 52 & B & 36 & $\mathrm{~B}$ & 51 & B \\
\hline Trees & 44 & $B$ & 52 & B & 60 & B & 62 & B & 63 & B & 47 & G \\
\hline Ship & 63 & $\mathrm{R}$ & 66 & B & 68 & B & 68 & B & 67 & B & 64 & $R$ \\
\hline Waterfall & 55 & G & 56 & $\mathrm{R}$ & 57 & $\mathrm{G}$ & 60 & $\mathrm{G}$ & 64 & $\mathrm{R}$ & 52 & G \\
\hline AVG & 59.95 & & 74.05 & & 74.75 & & 73.9 & & 73.9 & & 59.7 & \\
\hline R, G, B COUNT & 6,9 & & 8,7 & & 5,8 & & 6,8 & & 7,7 & & 7,10 & 3 \\
\hline
\end{tabular}

TABLE XXIV : LS 32 BINS TOTAL OF INTENSITIES

\begin{tabular}{|l|l|l|l|l|l|l|}
\hline LS & L1 & L2 & L3 & L4 & L5 & CD \\
\hline MAX & $\mathbf{9 5}$ & 92 & 92 & 93 & 93 & 66 \\
\hline AVG & $\mathbf{1 5}$ & 13 & 12 & 12 & 12 & 11 \\
\hline
\end{tabular}

TABLE XXV : LS 32 Bins Mean of InTEnsities

\begin{tabular}{|l|c|c|c|c|c|c|}
\hline LS & L1 & L2 & L3 & L4 & L5 & CD \\
\hline MAX & 18 & 21 & 21 & $\mathbf{3 3}$ & $\mathbf{3 3}$ & 20 \\
\hline AVG & 8 & 9 & 9 & $\mathbf{1 0}$ & 9 & 9 \\
\hline
\end{tabular}

TABLE XXVILSRR 32 BINS _ TOTAL OF INTENSITIES

\begin{tabular}{|c|c|c|c|c|c|c|}
\hline LSRR & L1 & L2 & L3 & L4 & L5 & CD \\
\hline MIN & $\mathbf{6}$ & 9 & 9 & 9 & 9 & 9 \\
\hline AVG & $\mathbf{6 0}$ & 69 & 70 & 69 & 68 & 62 \\
\hline
\end{tabular}

TABLE XXVII LSRR 32 BINS _ MEAN OF INTENSITIES

\begin{tabular}{|l|l|l|l|l|l|l|}
\hline LSRR & L1 & L2 & L3 & L4 & L5 & CD \\
\hline MIN & $\mathbf{3 0}$ & 32 & 33 & 33 & 33 & 43 \\
\hline AVG & $\mathbf{8 4}$ & $\mathbf{8 4}$ & $\mathbf{8 5}$ & $\mathbf{8 4}$ & $\mathbf{8 4}$ & $\mathbf{8 4}$ \\
\hline
\end{tabular}

TABLE XXVIII : LS 16 BINS TOTAL OF INTENSITIES

\begin{tabular}{|l|l|l|l|l|l|l|}
\hline LS & L1 & L2 & L3 & L4 & L5 & CD \\
\hline MAX & $\mathbf{8 6}$ & $\mathbf{7 8}$ & $\mathbf{7 9}$ & 81 & 81 & 23 \\
\hline AVG & $\mathbf{1 5}$ & 13 & 12 & 12 & 12 & 10 \\
\hline
\end{tabular}

TABLE XXIX : LS 16 Bins MEAN OF INTENSITIES

\begin{tabular}{|l|l|l|l|l|l|l|}
\hline LS & L1 & L2 & L3 & L4 & L5 & CD \\
\hline MAX & 23 & 24 & 38 & 38 & 38 & $\mathbf{7 8}$ \\
\hline AVG & 11 & 11 & $\mathbf{1 2}$ & 11 & $\mathbf{1 2}$ & $\mathbf{1 2}$ \\
\hline
\end{tabular}

TABLE XXX : LSRR 16 BINS TOTAL OF INTENSITIES

\begin{tabular}{|l|c|c|c|c|c|c|}
\hline LSRR & L1 & L2 & L3 & L4 & L5 & CD \\
\hline MIN & $\mathbf{7}$ & 10 & 10 & 10 & 10 & 8 \\
\hline AVG & $\mathbf{6 1}$ & 68 & 68 & 68 & 68 & 62 \\
\hline
\end{tabular}

TABLE XXXI : LSRR 16 BINS _ MEAN OF INTENSITIES

\begin{tabular}{|l|c|c|c|c|c|c|}
\hline \multirow{2}{*}{ LSRR } & \multicolumn{6}{|c|}{32 LSRR : MEAN } \\
\cline { 2 - 7 } & L1 & L2 & L3 & L4 & L5 & CD \\
\hline MAX & $\mathbf{3 1}$ & 37 & 36 & 37 & 39 & 38 \\
\hline AVG & $\mathbf{8 2}$ & $\mathbf{8 2}$ & $\mathbf{8 2}$ & $\mathbf{8 2}$ & $\mathbf{8 2}$ & 84 \\
\hline
\end{tabular}


In LSRR results obtained for 256 bins for total and mean of intensities, as we are interested in the discussion of best i.e Minimum LSRR, we have highlighted the minimum values obtained with respect to each measure in yellow color. The best among them is CD measure where we can see that the average of 20 queries and also the individual results the minimum among all is obtained for CD measure. Next best is L1 i.e $\mathrm{AD}$ measure. If we check the color performance here we found red is dominating in total of intensities and green in count of pixels in 256 bins approach.

Same process is applied to 32 and 16 bins approach for total and mean of intensities. Here we have considered only the max and average values for LS and minimum and average for LSRR parameters respectively. These results are shown in tables numbered from XXIV to XXXI. Best results are highlighted in yellow. Color analysis is also done for these results and we found in 32 as well as in 16 bins approach for mean of intensities green is better whereas for total of intensities red is better for parameter LSRR. Similarly in LS parameter we found for mean results red is performing better and for total of intensities blue is better.

\section{CONCLUSION}

This paper explores the simple histogram based bins approach for image retrieval. It actually explores the advantage of simple computations (histogram) for feature extraction process. Dimensionality reduction is also worked out by simple linear grouping of 256 bins of histogram to generate 32 and 16 bins out of 256 bins of original histogram. Performance evaluation is done using three parameters PRCP, LS and LSRR and discussed in previous section in detail. Here are the few conclusions drawn for the proposed algorithms.

The first important factor to be discussed is PRCP results. The best value obtained for PRCP is 8970 for 256 bins with count of pixels. We have extracted the best results from each approach discussed above as follows.

\begin{tabular}{|c|c|c|c|}
\hline Parameter & 256 Bins & 32 Bins & 16 Bins \\
\hline PRCP & $\mathbf{8 9 7 0}$ & 8442 & 8663 \\
\hline LS & $\begin{array}{c}\text { MAX- 83 } \\
\text { AVG- 17 }\end{array}$ & $\begin{array}{c}\text { MAX- 95 } \\
\text { AVG- 15 }\end{array}$ & $\begin{array}{c}\text { MAX- 86 } \\
\text { AVG- 15 }\end{array}$ \\
\hline LSRR & $\begin{array}{c}\text { MIN- 9 } \\
\text { AVG- 59 }\end{array}$ & $\begin{array}{c}\text { MIN-6 } \\
\text { AVG- 60 }\end{array}$ & $\begin{array}{c}\text { MIN-7 } \\
\text { AVG- 61 }\end{array}$ \\
\hline
\end{tabular}

Now the conclusion can be drawn easily from the above table that 256 bins are performing better as compared to 32 and 16 bins approach, for PRCP and for average value of LS and LSRR. But the computations require for 256 are more than that of 32 and 16 bins approaches which increases the time complexity as well.
Comparing the results based on type of feature vector we found that total of intensities is doing well in all cases as compared to mean of intensities.

As this paper has also explored the use of multiple similarity measures i.e first five orders of Minkowski from 1 to 5 named as L1 to L5 and the sixth one is cosine correlation measure. We have compared their performances too. We found that L1 i.e Absolute distance and $\mathrm{CD}$ i.e cosine correlation distances are producing good results as compared to other 4 similarity measures. The next one in queue is Euclidean distance which is most commonly used similarity measure in CBIR systems by many researchers.

\section{REFERENCES}

[1] Raimonodo Schettini, G. Ciocca, Silvia Zuffi, "Content-Based Image Retrieval at the End of the Early Years" Institute of Tecnology, Infomatiche Multimediali-In Color Imaging Science: Exploiting Digital , 2001.

[2] Arnold W.M, Marcel Worring, Simone Santini, "Content-Based Image Retrieval at the End of the Early Years", IEEE Transactions On Pattern Analysis And Machine Intelligence, Vol. 22, No. 12, December 2000.

[3] V. N. REDDY, K. SATYA PRASAD, "Content Based Image Retrieval Using Local Derivative Patterns", Journal of Theoretical and Applied Information Technology, 30th June 2011. Vol. 28 No.2, Publication of Little Lion Scientific R\&D, Islamabad PAKISTA.

[4] SHI Dongcheng, XU Lan, HAN Ungyan, "Image retrieval using both color and texture features", The Journal of China Universities Of Posts And Telecommunications Volume 14, Supplement, October 2007.

[5] Hui Yu, Mingjing Li, Hong-Jiang Zhang, "Color Texture Moments For Content-Based Image Retrieval", Image Processing. 2002. Proceedings. 2002 International Conference on (Volume:3 ) 24-28 June 2002, ISSN :1522-4880, DOI: 10.1109/ICIP.2002.1039125.

[6] Bikesh Kr. Singh1, G. R Sinha, Bidyut Mazumdar "Content Based Retrieval of $\mathrm{X}$ - ray Images Using Fusion of Spectral Texture and Shape Descriptors", 2010 International Conference on Advances in Recent Technologies in Communication and Computing, 9780-7695-4201-0/10 \$26.00 (c) 2010 IEEE.

[7] Nadia Baaziz, Omar Abahmane, Rokia Missaoui "Texture feature extraction in the spatial-frequency domain for content-based image retrieval", eprint arXiv:1012.5208, arXiv.org - cs - arXiv:1012.5208.

[8] Ramadass Sudhir , Lt. Dr. S. Santhosh Baboo "An Efficient CBIR Technique with YUV Color Space and Texture Features", Computer Engineering and Intelligent Systems, ISSN 2222-1719 (Paper) ISSN 2222-2863 (Online) www.iiste.org, Vol 2, No.6, 2011.

[9] Neetu Sharma., Paresh Rawat, and jaikaran Singh, "Efficient CBIR Using Color Histogram Processing, 
Signal \& Image Processing", An International Journal(SIPIJ) Vol.2, No.1, March 2011.

[10] A Vadivel, A K Majumdar, Shamik Sural, "Perceptually Smooth Histogram Generation from the HSV Color Space for Content Based Image Retrieval", Int. Conf. on Advances in Pattern Recognition (ICAPR2003), Calcutta, India, 248-251, 2003.

[11] Yixin Chen, James Z. Wang, "CLUE: Cluster-Based Retrieval of Images by Unsupervised Learning", IEEE Transactions on Image Processing, Vol. 14, No. 8, August 2005.

[12] H.Yu, M. Li, H J. Zhang and J. Feng, "Color Texture Moments for Content-Based Image Retrieval", Proc. Int. Conference on Image Processing, Volume III, 929-931, 2002.

[13] Gwangwon Kang, Junguk Beak, "Features Defined by Median Filtering on RGB Segments for Image Retrieval", Second UKSIM European Symposium on Computer Modeling and Simulation, 978-0-76953325-4/08 \$25.00 (C) 2008 IEEE, DOI 10.1109/EMS.2008.105.

[14] M. J. Swain and D. H.Ballard. Color indexing. International Journal of Computer Vision, 7(1):11 32, 1991.

[15] P.S.Suhasini , Dr. K.Sri Rama Krishna “CBIR Using Color Histogram Processing”, Journal of Theoretical and Applied Information Technology, 2005 - 2009 JATIT.

[16] Nam Yee Kim, Kang Soo You, Gi-Hyoung Yoo, Hoon Sung Kwak, "An Efficient Histogram Algorithm for Retrieval from Lighting ChangedImages", Future Generation Communication and Networking Symposia, 2008. FGCNS '08. Second International Conference on (Volume:3 ), ISBN- 9781-4244-3430-5, 13-15 Dec. 2008.

[17] Wang Database: http://wang.ist.psu.edu/docs/related/.

[18] Wei-Min Zheng, Zhe-Ming Lu, "Color Image Retrieval Schemes Using Index Histograms Based On Various Spatial-Domain Vector Quantizers", International Journal of Innovative Computing, Information and Control ICIC, 2006 ISSN 1349-4198 Volume 2, Number 6, December.

[19] H. B. Kekre, Ms. Kavita Sonawane "Linear Equation in Parts as Histogram Specification for CBIR Using Bins Approach", International Journal of Engineering Research and Development e-ISSN: 2278-067X, pISSN: 2278-800X, www.ijerd.com Volume 4, Issue 4 (October 2012), PP. 73-85.

[20] H. B. Kekre, Ms. Kavita Sonawane "Histogram Partitioning for Feature Vector Dimension Reduction in Bins Approach for CBIR", International Journal of Electronics Communication and Computer Engineering Volume 3, Issue 6, ISSN (Online): 2249 071X, ISSN (Print): 2278-4209 PNO 1422.

[21] Simone Santini, Ramesh Jain, "Similarity Measures" IEEE Transactions On Pattern Analysis And Machine Intelligence, Vol. 21, No. 9, September 1999.

[22] John P, Van De Geer, "Some Aspects of Minkowski distance", Department of data theory, Leiden University. RR-95-03.
[23] Gang Qian, Shamik Sural, Yuelong Gu† Sakti Pramanik, "Similarity between Euclidean and cosine angle distance fornearest neighbor queries", SAC'04, March 14-17, 2004, Nicosia, Cyprus Copyright 2004 ACM 1-58113-812-1/03/04.

[24] Ellen Spertus, Mehran Sahami, Orkut Buyukkokten, "Evaluating Similarity Measures:A LargeScale Study in the Orkut Social network" Copyright 2005ACM.The definitive version was published in KDD '05, August 2124, 2005http://doi.acm.org/10.1145/1081870.1081956.

[25] Dengsheng Zhang and Guojun Lu "Evaluation Of Similarity Measurement for Image Retrieval" www. Gscit.monash.edu.au/ dengs/resource/papers/icnnsp0 3.

[26] Md Monirul Islam, Dengsheng Zhang and Guojun Lu, "Comparison of Retrieval Effectiveness of Different Region Based Image Representations", 1-4244-09837/07/\$25.00 @2007 IEEE, ICICS 2007.

[27] Thomas Deselaers, Daniel Keysers, and Hermann Ney, "Classification Error Rate for Quantitative Evaluation of Content-basedImage Retrieval Systems", http://www.robots.ox.ac.uk/ vgg/data.

[28] Danzhou Liu, Member, Kien A. Hua, Khanh Vu, "Fast Query Point Movement Techniques for Large CBIR Systems" IEEE Transactions On Knowledge And Data Engineering, VOL. 21, NO. 5, MAY 2009.

[29] Tanusree Bhattacharjee, Biplab Banerjee, Nirmalya Chowdhury, "An Interactive Content Based Image Retrieval Technique and Evaluation of its Performance in High Dimensional and Low Dimensional Space", International Journal of Image Processing (IJIP), Volume(4) : Issue(4).

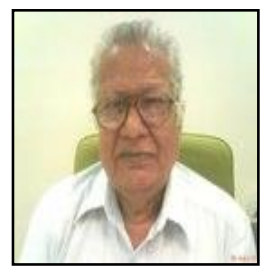

Dr. H. B. Kekre has received B.E. (Hons.) in Telecomm. Engg. from Jabalpur University in 1958,M.Tech (Industrial Electronics) from IIT Bombay in 1960, M.S. Engg. (Electrical Engg.) from University of Ottawa in 1965 and Ph.D. (System Identification) from IIT Bombay in $1970 . \mathrm{He}$ has worked Over 35 years as Faculty of Electrical Engineering and then HOD Computer Science and Engg. at IIT Bombay. For last 13 years worked as a Professor in Department of Computer Engg. at Thadomal Shahani Engineering College, Mumbai. He is currently Senior Professor working with Mukesh Patel School of Technology Management and Engineering, SVKM's NMIMS University, Vile Parle(w), Mumbai, INDIA. He has guided 17 Ph.D.s, 150 M.E./M.Tech Projects and several B.E./B.Tech Projects. His areas of interest are Digital Signal processing, Image Processing and Computer Networks. He has more than 450 papers in National / International Conferences / Journals to his credit. Recently twelve students working under his guidance have received best paper awards. Five of his students have been awarded $\mathrm{Ph}$. D. of NMIMS 
University. Currently he is guiding eight Ph.D. students. $\mathrm{He}$ is member of ISTE and IETE.

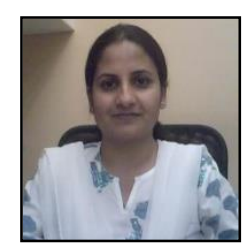

Ms. Kavita V. Sonawane has received M.E (Computer Engineering) degree from Mumbai University in 2008. Pursuing Ph.D. from Mukesh Patel School of Technology Management and Engineering,
INDIA. She has more than 10 years of experience in teaching. Currently working as Assistant professor in Department of Computer Engineering at St. Francis Institute of Technology Mumbai. Her area of interest is Image Processing, Data structures and Computer Architecture. She has 23 papers in National/ International conferences / Journals to her credit. She is life time member of ISTE.

SVKM's NMIMS University, Vile Parle (w), Mumbai,

How to cite this paper: H. B. Kekre, Kavita Sonawane,"Histogram Bins Matching Approach for CBIR Based on Linear grouping for Dimensionality Reduction", IJIGSP, vol.6, no.1, pp. 68-82, 2014.DOI: 10.5815/ijigsp.2014.01.10 